Images in...

\title{
Severe type of adult jejunal intussusception caused by long intestinal tube in a patient with intestinal obstruction due to cecal carcinoma
}

\author{
Takahisa Fujikawa, ${ }^{1}$ Akira Tanaka, ${ }^{1}$ Seiichiro Tada, ${ }^{1}$ Kei Shiraishi ${ }^{2}$ \\ ${ }^{1}$ Surgery Department, Kokura Memorial Hospital, Kitakyushu, Fukuoka, Japan; \\ ${ }^{2}$ Gastroenterology Department, Kokura Memorial Hospital, Kitakyushu, Fukuoka, Japan
}

Correspondence to Dr Takahisa Fujikawa, fujikawa-t@kokurakinen.or.jp

\section{DESCRIPTION}

A 74-year-old male presented with abdominal cramping and emesis. A CT and colonoscopy revealed dilated jejunum and ileum due to advanced cecal cancer. A long intestinal tube was progressed via nasogastric route for intestinal decompression, and the patient's symptoms were temporarily relieved. On day 7 , the patient again developed signs and symptoms of obstruction. A repeated CT scan revealed that the ileum was almost decompressed but a severe jejuno-jejunal intussusception associated with the long tube was observed (figure 1). Due to the patient's clinical deterioration, abdominal exploration was performed and, in addition to a cecal mass, a severe antegrade jejuno-jejunal intussusception with pressure necrosis around the tube was separately found (figure 2). Right hemi-colectomy and partial jejunal resection were performed. After stormy postoperative course, the patient developed severe aspiration

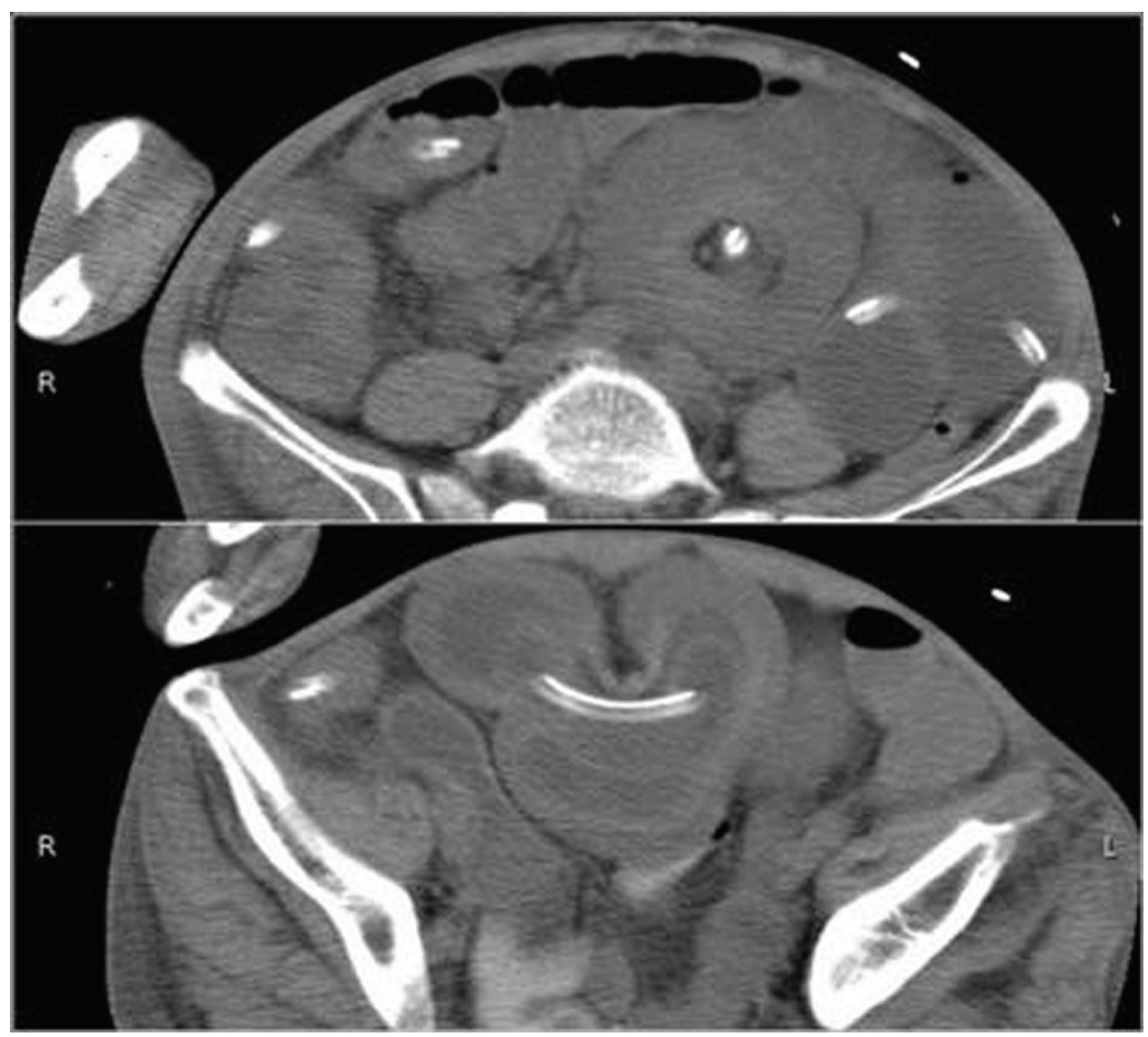

Figure 1 (A, B) CT images showed severe type of jejuno-jejunal intussusception, with invagination of jejunal intussusceptum into severely dilated intussuscipiens in association with a long intestinal tube. (A) showed a typical 'target sign' around the intestinal tube (arrows). (B), a unique 'Mickey Mouse'-shaped invagination suggesting severe type of intussusception (arrows), is a slightly more caudal image than that shown in $(A)$. 


\section{BMJ Case Reports}

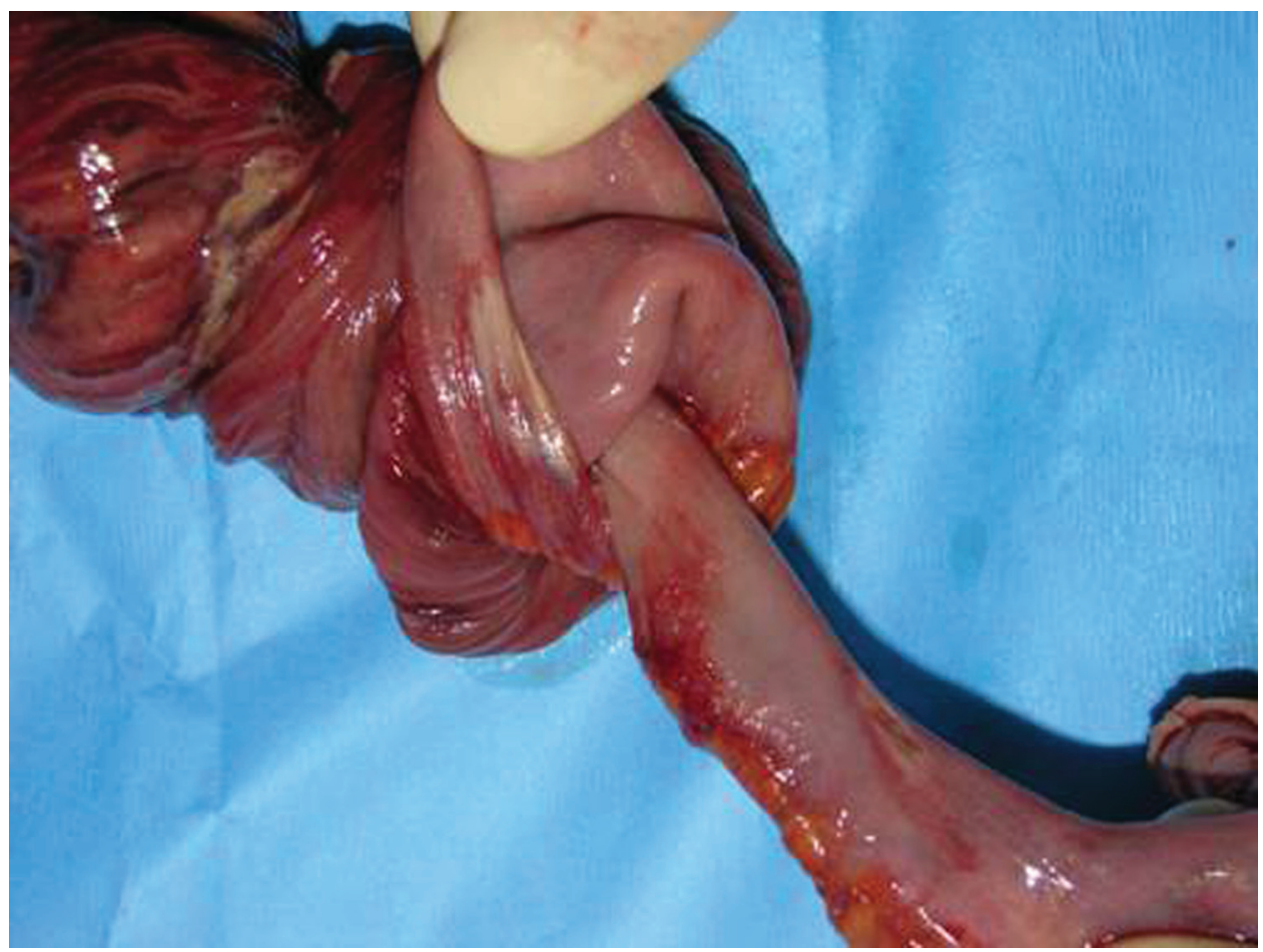

Figure 2 Resected segment of jejunum showed an antegrade jejunal intussusception with ischemic changes and pressure necrosis.

pneumonitis and disseminated intravascular coagulation and expired. Intussusception in the adult is an uncommon event, with proximal jejunal intussusception secondary to a long tube, especially a severe type like in the current case, considered relatively rare. ${ }^{1-3}$ Compared to distal small bowel, the loops of proximal small bowel are not usually telescoped as compactly as distal loops. ${ }^{3}$ In our case, as folds of small intestine may become telescoped over the long tube due to ongoing propulsive peristalsis over severely dilated proximal intestine. Most cases of adult jejunal intussusception are difficult to diagnose, and intestinal resection was frequently needed. ${ }^{1-3}$ Noninvasive imaging modalities including high resolution CT scan is the key to establish its early diagnosis. ${ }^{3}$ An index of high suspicion and early diagnosis is mandatory to avoid progression to severe type of long tube-induced jejunal intussusception and to improve outcome.

Competing interests None.

Patient consent Obtained.

\section{REFERENCES}

1. Shub HA, Rubin RJ, Salvati EP. Intussusception complicating intestinal intubation with a long Cantor tube: report of four cases. Dis Colon Rectum 1978;21:130-4.

2. Peskin SR, Langevin RE JrBanks PA. Proximal jejunal intussusception associated with a long tube. Dig Dis Sci 1986;31:657-60.

3. Wilson $\mathbf{C H}$, White SA. Images in clinical medicine. Small-bowel intussusception. N Engl J Med 2007;357:e30.

This pdf has been created automatically from the final edited text and images.

Copyright 2011 BMJ Publishing Group. All rights reserved. For permission to reuse any of this content visit http://group.bmj.com/group/rights-licensing/permissions.

BMJ Case Report Fellows may re-use this article for personal use and teaching without any further permission.

Please cite this article as follows (you will need to access the article online to obtain the date of publication)

Fujikawa T, Tanaka A, Tada S, Shiraishi K. Severe type of adult jejunal intussusception caused by long intestinal tube in a patient with intestinal obstruction due to cecal carcinoma. BMJ Case Reports 2011;10.1136/bcr.05.2011.4256, date of publication

Become a Fellow of BMJ Case Reports today and you can:

- Submit as many cases as you like

- Enjoy fast sympathetic peer review and rapid publication of accepted articles

- Access all the published articles

- Re-use any of the published material for personal use and teaching without further permission

For information on Institutional Fellowships contact consortiasales@bmjgroup.com

Visit casereports.bmj.com for more articles like this and to become a Fellow 